\title{
Laparoscopic Treatment for Secondary Ureteropelvic Junction Obstruction
}

\author{
Hassaan A. Gad*1, M. Zaki Eldahshoury ${ }^{1}$, Mohammed M. Hussein ${ }^{1}$, Ahmed Hammady ${ }^{2}$ \\ ${ }^{1}$ Department of Urology, Faculty of Medicine - Aswan University, ${ }^{2}$ Department of Urology, \\ Faculty of Medicine - Sohag University \\ *Corresponding author: Hassaan Ali Ahmed, Mobile: (+20) 01113730199, E-Mail: hassan.ali@aswu.edu.eg
}

\begin{abstract}
Background: Pelviureteric junction obstruction (PUJO) is one of the most frequent congenital anomalies of the urinary tract system. It is associated with pain, hydronephrosis, urinary tract infections, and eventually loss of renal function.

Objective: To evaluate our institution in laparoscopic management of pelviureteric junction obstruction after failed open or laparoscopic surgery for pyeloplasty.

Patients and methods: This study was conducted on 45 patients in two centers, Aswan Urology Department, and Sohage Urology Department. All of them have secondary pelviureteric junction obstruction.

Results: This study included 24 females and 21 males, with the mean age of $30.2 \pm 7.5$ years (range 21 to 45 years), failed previous repair on the left side was in 29 cases while it was in 16 cases on the right side. Regarding BMI, it ranged from 21 to 30 with mean of $24.9 \pm 3.1 \mathrm{~kg} / \mathrm{m}^{2}$. The mean time after failure of primary pyeloplasty in both genders was $21.3 \pm 8.2$ months with a range of 10 -38 months. The preoperative total renal function by DTPA was $80.7 \pm 26.5$. All cases were done laparoscopically without conversion to open surgery with a mean operative time of $154.9 \pm 25.4$ minutes (range from 80 to 185 minutes). The intra operative etiological finding of previous failure were peripelvic fibrosis and scarring in 34 cases, proximal ureteric stricture in 4, missed lower pole crossing vessels at initial surgery in 5 and a kink at the PUJ associated with redundant pelvis in two patients.
\end{abstract}

Conclusion: Laparoscopic pyeloplasty is an effective minimal invasive alternative to open surgery in treatment of secondary pelviureteric junction obstruction.

Keywords: Laparoscopic treatment, Pyeloplasty, Repyeloplasty, Secondary, UPJO.

\section{INTRODUCTION}

Pelviureteric junction obstruction (PUJO) of the kidney can cause pain, recurrent urinary tract infections, hydronephrosis and loss of renal unit function. Surgical intervention is often required and numerous treatment strategies have been employed. These modalities have changed with time.

PUJO can be considered congenital or acquired and recent algorithms for the management of PUJO have highlighted the importance of establishing intrinsic (e.g. atreteic or stenosed ureteral segment) or extrinsic (e.g. lower pole crossing vessel) compression in deciding optimal primary management ${ }^{(\mathbf{1})}$.

Following the description in 1949 by Anderson and Hynes ${ }^{(2)}$, open dismembered pyeloplasty became the gold standard. Endoscopic management in the form of endopyelotomy was introduced in 1990's and success rates up to $70-90 \%$ was achieved ${ }^{(3)}$. Laparoscopic pyeloplasty was first described in $1993^{(4)}$, and success rates comparable to open pyeloplasty of $84-98 \%$ are quoted ${ }^{(5)}$.

Some now believe that laparoscopic pyeloplasty is the new gold standard, having superior outcomes compared to endopyelotomy and less morbidity compared to open pyeloplasty.

Other modalities for primary intervention include robotic pyeloplasty, which may have equivalent results to laparoscopy, but is not as widely available and has less follow-up to date ${ }^{(6)}$.
Definitions of treatment success and failure vary within the literature. Failure can be considered as the inability to improve symptoms, dynamic renographic parameters, renal unit function or hydronephrosis ${ }^{(7)}$.

Other success criteria have included symptomatic resolution (i.e. more than $80 \%$ pain relief) associated with stable or improved renal function and improved washout from the renal pelvis (i.e. T1/2 $<20 \mathrm{~min}$ ). On renal scan a combination of reduction of symptoms and an improvement in renogram or intravenous urogram has also been used ${ }^{(\mathbf{8})}$.

Failure of primary treatment can be considered as early or late, both scenarios will be termed "secondary PUJO." The causes of failed treatment include poor surgical technique, an "irreparable pelvicaliceal system," PUJ ischemia with re-stenosis, anastomotic leak with urinoma and fibrosis, a missed crossing vessel, which can occur in $18 \%-50 \%$ of cases, ureteric stent malfunction and diabetes ${ }^{(7)}$.

Most treatment failures present within the first 18 months following the procedure. However, secondary PUJO has been identified in patients up to 5 years after primary treatment. This suggests that a prolonged follow-up may be necessary in these patients (9).

The aim of this study was to evaluate our institution in laparoscopic management of pelviureteric junction obstruction after failed open or laparoscopic surgery for pyeloplasty. 


\section{PATIENTS AND METHOD}

Study design: A prospective clinical study included 45 adult patients of both genders with PUJ obstruction after previous renal surgery. The study was conducted in the urology departments, Aswan University Hospital and Sohag University Hospital.

Inclusion criteria: All adult patients with PUJ obstruction after renal surgery (open, endoscopic or laparoscopic previously repaired).

\section{Exclusion criteria:}

1. Patient having poor ipsilatral renal function $<15 \%$.

2. Patients with UPJO require procedures other than pyeloplasty as

a. Obstruction of neoplastic nature.

b. Severe uncompensated cardiopulmonary disease.

c. Pediatric patient.

d. Pregnant women.

Ethical consideration: All patients were thoroughly informed about the procedures and informed written consents were fulfilled. Approval from Ethical Committee of Aswan Faculty of Medicine was obtained.

All Patients individuals were subjected to the following:

Preoperative evaluation:

Detailed history, physical examination and routine laboratory work-up:

- Renal function evaluation.

- Bleeding and coagulation profile.

- Liver function evaluation.

- Blood sugar level.

- Urine analysis.

- Medical fitness for surgical intervention. Imaging studies:

- Renal US.

- Contrast study (IVU or CTU).

- Diuretic renogram

- Retrograde pyelography when needed.

\section{Statistical analysis}

Data collected from thorough history, basic clinical examination, laboratory investigations and outcome measures were coded, entered and analyzed using Microsoft Excel software. Data were then imported into Statistical Package for the Social Sciences (SPSS) version 20. 0.

According to the type of data, qualitative were represented as number and percentage and quantitative were represented as mean $\pm \mathrm{SD}$.

The following tests were used: Chi square test $\left(\mathrm{X}^{2}\right)$ for difference and association of qualitative variables and Mann Whitney test for differences between quantitative independent groups. $\mathrm{P}$ value was set at $\leq 0.05$ for significant results.

\section{RESULTS}

This study included 24 females and 21 males, with the mean age of $30.2 \pm 7.5$ years (ranged from 21 to 45 years).

Failed previous repair on the left side was in 29 cases while it was 16 cases on the right side. Regarding BMI, it ranged from 21to 30 with mean of $24.9 \pm 3.1$ $\mathrm{kg} / \mathrm{m}^{2}$. The mean time after failure of primary pyeloplasty in both genders was $21.3 \pm 8.2$ months (rang 10-38 months).

The preoperative total renal function by DTPA was $80.7 \pm 26.5$ (Table 1$)$.

The main complaint of the patients were loin pain in about $75 \%$ of cases , followed by accidently discovered UPJO in form of lack of radiological improvement after primary repair, other patient presented by recurrent urinary tract infection (UTI), or infected obstructed kidney (Table 2).

Table (1): Baseline demographic data.

\begin{tabular}{|l|c|}
\hline Age & $30.2 \pm 7.5$ \\
\hline $\begin{array}{l}\text { Sex } \\
\text { Male/female }\end{array}$ & $21 / 24$ \\
\hline $\begin{array}{l}\text { Diseased side } \\
\text { Rt./Lt. }\end{array}$ & $16 / 29$ \\
\hline Body mass index (kg/m2) & $24.9 \pm 3.1$ \\
\hline Mean time of failure/months & $21.3 \pm 8.2$ \\
\hline Renal function/DTPA/ml & $80.7 \pm 26.5$ \\
\hline
\end{tabular}

Table (2): Complaint of the patients.

\begin{tabular}{|l|c|}
\hline \multicolumn{1}{|c|}{ Complaint } & Patients Number \\
\hline Rt. loin pain & 13 \\
\hline Lt loin pain & 16 \\
\hline $\begin{array}{l}\text { lack of radiological } \\
\text { improvement }\end{array}$ & 7 \\
\hline Recurrent UTI & 7 \\
\hline Infected kid with PCN & 2 \\
\hline Total number & 45 \\
\hline
\end{tabular}

All cases were done laparoscopically without conversion to open surgery with mean operative time of $154.9 \pm 25.4$ minutes (range, 80 to 185 minutes).

The intra operative etiological finding of previous failure were peripelvic fibrosis and scarring in 34 cases, proximal ureteric stricture in 4 , missed lower pole crossing vessels at initial surgery in 5 and a kink at the PUJ associated with redundant pelvis in two patients.

Intra operative blood loss estimated by hemoglobin and hematocrit value loss, no needed for intra or postoperative blood transfusion with mean estimated blood loss in ml was $77.8 \pm 32.8$ (Table 3 ). 
Table (3) Intraoperative data presentation

\begin{tabular}{|l|c|}
\hline Mean operative time (min) & $154 \pm 25.4$ \\
\hline Type of repair & $\begin{array}{c}\text { Anderson- } \\
\text { Hynes }\end{array}$ \\
\hline Mean blood loss (ml) & $77.8 \pm 32.8$ \\
\hline Intraoperative complication \% & $6.7 \%$ \\
\hline Mean hospital stay (days) & $3.8 \pm 1.2$ \\
\hline Postoperative complication & $13.3 \%$ \\
\hline Success rate \% & $93.3 \%$. \\
\hline
\end{tabular}

Intraoperative complications were reported in 3 cases $(6.7 \%)$ where in two patients there was bleeding due to accidental injury of the gonadal vein during dissection of dense fibrosis. It was controlled without the need of blood transfusion or conversion into open surgery through holding and ligation of the vein with no further complications. Another patient showed colonic serosal injury, which occurred in patient with right sided PUJO after failed open pyeloplasty since 1 year ago.

Intraoperatively, the patient showed dense adhesions and during dissection by scissor, injury occurred and early discovered and was successfully sutured intraoperative. In five cases, we needed complete mobilization of the kidney to allow tension free anastomosis of pelvis to the ureter (Table 4).

Table (4): The etiology of 2ryPUJO.

\begin{tabular}{|l|c|}
\hline \multicolumn{1}{|c|}{ Etiology } & Number \\
\hline Fibrosis And Scarring & 34 \\
\hline Ureteric Stricture & 4 \\
\hline Crossing Vessels & 5 \\
\hline Kink At The PUJ & 2 \\
\hline \multicolumn{1}{|c|}{ Total } & 45 \\
\hline
\end{tabular}

\section{DISCUSSION}

PUJO represents approximately $40 \%$ of the urologic diseases diagnosed. Frequently it does not require invasive treatment, but only clinical and laboratorial follow-up. In about $20 \%$ of the cases, surgical correction of the PUJO is necessary in order to preserve renal function. If left untreated, it may lead to a syndrome with blockade and reduction of the urine flow, dilatation of the urinary tract, hydronephrosis, and other symptoms ${ }^{(\mathbf{1 0})}$. Several aspects of urinary obstruction have been studied. Urinary tract obstruction results in renal compensatory mechanisms and may cause irrecoverable functional loss and histological alterations ${ }^{(11)}$.

In this prospective study carried out on 45 patients presented to our Urology Department to evaluate the results of laparoscopic management of ureteropelvic junction obstruction after failed open or laparoscopic surgery for pyeloplasty regarding the technique, the intra-operative, postoperative results and the rate of success in comparison to previous literatures.
In this study, the mean operative time was $154.9 \pm 25.4$ minutes. This is less than the results that reported in the literatures, in the study of Nishi $\boldsymbol{e t}$ al.????? who recorded mean operative time of 269 (165-525) minutes and Basiri et al. ${ }^{(12)}$ who reported treatment of secondary UPJO with average operating time of $254 \pm 82$ minutes. However, they used different techniques in pyeloplasty repair and all of their patients had long segment stricture with a lot of time releasing the upper ureter and renal pelvis to decide type of repair. In addition, Schuster et al. (13) reported a mean operative time of $370 \pm 76.9$ minutes. The patients in their study showed more fibrosis and scaring at the UPJ site due to the multiple previous procedures, which may explains the long operative time.

In our study laparoscopic pyeloplasty was completed successfully in all cases, with no one converted to open surgery nor requiring blood transfusion and mean blood loss was about $77.8 \pm 32.8$ $\mathrm{ml}$. This is similar or less than other literatures where Francesco et al. ${ }^{(14)}$ reported mean blood loss of $122 \pm$ $73 \mathrm{ml}$ with significant difference. Levin et al.????? showed a blood loss about $131 \mathrm{ml}$ (range 100-250 ml), which occurred due to the multiple previous endoscopic procedures of their patients with massive scaring and adhesions. Other intra operative complication in our study one case of colonic serosal injury and two cases of accidental injury of the gonadal vein. Moon et al. ${ }^{(15)}$ experienced in his study for LP 3 major intraoperative complications in which two cases required conversion to open surgery and one another showed colonic injury with subsequent right hemicolectomy.

Due to low success rate and inconsistent longterm results of minimal invasive procedures such as balloon dilation and endopyelotomy and their role in selected cases using inclusion criteria of stricture $<2$ $\mathrm{cm}$, renal function $>25 \%$ and the absence of severe hydronephrosis. So it cannot be considered an ideal option in secondary PUJO management.in this study of 45 patients achieving a success rate of $93.3 \%$ by symptom relief and radiological improvement ${ }^{(16)}$.

\section{CONCLUSION}

Laparoscopic pyeloplasty is an effective minimal invasive alternative to open surgery in treatment of secondary pelviureteric junction obstruction.

Conflict of interest: The authors declare no conflict of interest.

Funding sources: The authors have no funding to report.

\section{REFERENCES}

1. Rassweiler J, Subotic S, Feist-Schwenk M et al. (2007): Minimally invasive treatment of ureteropelvic junction obstruction: Long-term experience with an algorithm for 
laser endopyelotomy and laparoscopic retroperitoneal pyeloplasty. J Urol., 177: 1000-5.

2. Anderson J, Hynes W (1949): Retrocaval ureter: A case diagnosed pre-operatively and treated successfully by a plastic operation. Br J Urol., 21: 209-14.

3. Webber R, Pandian S, McClinton S et al. (1997): Retrograde balloon dilatation for pelviureteric junction obstruction: Long-term follow-up. J Endourol., 11: 23942.

4. Schuessler W, Grune M, Tecuanhuey L et al. (1993): Laparoscopic dismembered pyeloplasty. J Urol., 150: 1795-9.

5. Maynes L, Levin B, Webster T et al. (2008): Measuring the true success of laparoscopic pyeloplasty. J Endourol., 22: 1193-8.

6. Mufarrij P, Woods M, Shah O et al. (2008): Robotic dismembered pyeloplasty: A 6-year, multi-institutional experience. J Urol., 180: 1391-6.

7. Tan H, Ye Z, Roberts W et al. (2011): Failure after laparoscopic pyeloplasty: Prevention and management. J Endourol., 25: 1457-62.

8. Albani J, Yost A, Streem S (2004): Ureteropelvic junction obstruction: Determining durability of endourological intervention. J Urol., 171: 579-82.

9. Dimarco D, Gettman M, McGee S et al. (2006): Longterm success of antegrade endopyelotomy compared with pyeloplasty at a single institution. J Endourol., 20: 70712.
10. Halachmi S, Pillar G (2008): Congenital urological anomalies diagnosed in adulthood management considerations. Journal of Pediatric Urology, 4 (1): 2-7.

11. MacLellan D, Mataija D, Doucette A et al. (2011): Alterations in urinary metabolites due to unilateral ureteral obstruction in a rodent model," Molecular BioSystems, 7 (7): 2181-2188.

12. Basiri A, Behiati S, Zand S et al. (2007): Laparoscopic pyeloplasty in secondary ureteropelvic junction obstruction after failed open surgery. J Endourol., 21: 1045-1051.

13. Schuster T, Jacobs B, Gayed B et al. (2010): Preliminary experience with laparoscopic ureteropelvic junction release in the treatment of ureteropelvic junction obstruction. J Endourol., 24: 393-396.

14. Francesco C, Maurizio F, Luigi P et al. (2017): Laparoscopic management of recurrent ureteropelvic junction obstruction following pyeloplasty: a single surgical team experience. Int Braz J Urol., 43 (3): 512 517.

15. Moon D, El-Shazly M, Chang C et al. (2006): Laparoscopic pyeloplasty: Evolution of a new gold standard. Urology, 67: 932-36.

16. Butani R, Eshghi $M$ (2008): Cold-knife retrograde endopyelotomy: a long-term follow-up. J Endourol., 22: 657-660. 